\title{
Diagnóstico Parcial do Potencial Produtivo de Beneficiários da Resex Tapajós-Arapiuns para Atendimento ao PNAE (Programa Nacional de Alimentação Escolar)
}

\author{
Hillary Lyn Soares Coelho ${ }^{1}$ \& Jackeline Nóbrega Spínola ${ }^{2}$
}

\author{
Recebido em 13/08/2020 - Aceito em 04/10/2020 \\ ${ }^{1}$ Universidade Federal do Oeste do Pará/UFOPA, Brasil. < hillarypaschoal@hotmail.com>. \\ ${ }^{2}$ Instituto Chico Mendes de Conservação da Biodiversidade/ICMBio, Reserva Extrativista Tapajós-Arapiuns, Santarém/PA, Brasil . \\ < jackeline.nobrega@icmbio.gov.br >
}

\begin{abstract}
RESUMO - A partir da Lei da Alimentação Escolar, destaca-se o apoio ao desenvolvimento sustentável, com incentivos à aquisição de gêneros alimentícios através do Programa Nacional de Alimentação Escolar. Entretanto, a Reserva Extrativista Tapajós-Arapiuns, localizada no Pará, contém escolas que no momento carecem de infraestrutura e de nutrientes adequados. O objetivo do trabalho foi levantar informações junto aos beneficiários da RESEX sobre seu potencial de produção alimentícia para atendimento da rede pública escolar comunitária. Foram realizadas reuniões em 24 Escolas-Polo, a partir da metodologia do Diagnóstico Rápido e Participativo de Agroecossistemas, foram obtidas informações de infraestrutura, alimentos disponíveis e a produtividade anual por cada família. Todas as escolas possuem gerador de energia, fator limitante pois a RESEX não possui rede elétrica. O transporte dos alimentos até as escolas não possui as adequações necessárias, como as câmaras frias. Foram mencionados no diagnóstico 64 gêneros alimentícios pelos comunitários, sendo os mais indicados a farinha e seus derivados e a galinha caipira. Os resultados demonstraram que existe produção e diversidade de produtos, porém não foi possível comprovar a produção de excedentes para atendimento satisfatório das demandas da alimentação da rede pública escolar comunitária, em virtude de poucos produtores terem aderido ao preenchimento dos questionários, apenas $10 \%$ das unidades familiares de 3500 famílias. Evidencia-se que, apesar das dificuldades com o transporte e refrigeração, os comunitários demostraram interesse e possuem disponibilidade para a comercialização dos gêneros junto ao PNAE, entretanto é necessário adequar o beneficiamento dos produtos para a realidade da unidade de conservação.
\end{abstract}

Palavras-chave: Segurança alimentar; políticas públicas; agricultura familiar.

\section{Partial Diagnosis of the Productive Potential of RESEX Tapajós-Arapiuns Beneficiaries to Attend to the PNAE (National School Feeding Program)}

ABSTRACT - From the School Food Law, support for sustainable development stands out, with incentives for the acquisition of foodstuffs through the National School Food Program. However, the Tapajós-Arapiuns Extractive Reserve, located in Pará, is a choice that currently lacks adequate infrastructure and nutrients. The objective of the work was to gather information from the RESEX beneficiaries about their potential for food production to serve the public school community network. Meetings were held in 24 Polo Schools, based on the Rapid and Participative Diagnosis of Agro-ecosystems methodology, with information on infrastructure, available food and an annual productivity for each family. All schools have an energy generator, a limiting factor as RESEX does not have a power grid. The transportation of food to schools does not have the necessary facilities, such as cold rooms. In the diagnosis, 64 foodstuffs were recorded for the related ones, the most indicated being flour and its derivatives and free-range chicken. The results showed that there is production and diversity of products, but it was not possible to prove the production of surpluses to satisfactorily meet the demands of the public school community food supply, due to the fact that few results adhered to the questionnaires, only $10 \%$ of the units 3500 families. It is evident that despite the difficulties with transportation and refrigeration, the competent ones showed interest and availability for the commercialization of the products with the PNAE, however it is necessary to adapt the processing of the products to the reality of the Conservation Unit.

Keywords: Food security; public policy; family farming. 


\section{Diagnóstico Parcial del Potencial Productivo de los Beneficiarios de RESEX Tapajós-Arapiuns para Atender el PNAE (Programa Nacional de Alimentación Escolar)}

RESUMEN - Desde la Ley de Alimentación Escolar, se destaca el apoyo al desarrollo sostenible, con incentivos para la adquisición de alimentos a través del Programa Nacional de Alimentación Escolar. Sin embargo, la Reserva Extractiva Tapajós-Arapiuns, ubicada en Pará, es una opción que actualmente carece de infraestructura y nutrientes adecuados. El objetivo del trabajo fue recopilar información de los beneficiarios de RESEX sobre su potencial de producción de alimentos para servir a la red comunitaria de escuelas públicas. Se realizaron reuniones en 24 Escuelas de Polo, con base en la metodología Diagnóstico Rápido y Participativo de Agroecosistemas, con información sobre infraestructura, alimentos disponibles y una productividad anual para cada familia. Todas las escuelas tienen un generador de energía, un factor limitante ya que RESEX no tiene una red eléctrica. El transporte de alimentos a las escuelas no cuenta con las instalaciones necesarias, como cámaras frigoríficas. En el diagnóstico se registraron 64 alimentos para los relacionados, siendo los más indicados la harina y sus derivados y el pollo de corral. Los resultados mostraron que existe producción y diversidad de productos, pero no fue posible acreditar la producción de excedentes para atender satisfactoriamente las demandas de abasto alimentario de la comunidad escolar pública, debido a que pocos resultados se adhirieron a los cuestionarios, solo el $10 \%$ de las unidades 3500 familias. Es evidente que a pesar de las dificultades con el transporte y refrigeración, los competentes mostraron interés y disponibilidad para la comercialización de los productos con el PNAE, sin embargo es necesario adecuar el procesamiento de los productos a la realidad de la Unidad de Conservación.

Palabras claves: Seguridad alimentaria; política pública; agricultura familiar.

\section{Introdução}

O Programa Nacional de Alimentação Escolar (PNAE) é um dos maiores programas de alimentação escolar do mundo e um dos mais antigos do Brasil. Em 2009, novas diretrizes de execução do PNAE foram estabelecidas, após a edição da Lei n. 11.947/2006, da Alimentação Escolar (LAE). Segundo o Artigo 10, "alimentação escolar é o alimento oferecido no ambiente escolar, independentemente de sua origem, durante todo o período letivo" (BRASIL, 2009).

Conforme essa mesma Lei, em seu Artigo $2^{\circ}$, que define suas diretrizes, podemos destacar:

- apoiar ao desenvolvimento sustentável, com incentivos para a aquisição de gêneros alimentícios diversificados, e produzidos em âmbito local, preferencialmente, junto aos produtores das referidas comunidades;

- a participação da comunidade no controle social e acompanhamento das ações estatais, na perspectiva da segurança alimentar e nutricional;

- o respeito à cultura, às tradições e hábitos alimentares saudáveis e diversificados.
Esse mesmo diploma legal destaca ainda em seu art. $14^{\circ}$ :

Do total dos recursos financeiros repassados pelo FNDE, no âmbito do PNAE, no mínimo $30 \%$ (trinta por cento) deverão ser utilizados na aquisição de gêneros alimentícios diretamente da agricultura familiar e do empreendedor familiar rural ou de suas organizações, priorizando-se os assentamentos da reforma agrária, as comunidades tradicionais indígenas e comunidades quilombolas. (BRASIL, 2009)

Essa importante política pública ainda não é uma realidade presente na vida dos moradores e das comunidades escolares da Reserva Extrativista (RESEX) Tapajós-Arapiuns, gerida pelo Instituto Chico Mendes de Conservação da Biodiversidade (ICMBio). Tal fato é evidenciado a partir das discussões junto aos fóruns de participação social na unidade de conservação (UC), como o Conselho Deliberativo, quando, nas últimas três reuniões ordinárias de 2019, ficam evidentes os relatos e queixas quanto à deficiência nutricional dos produtos ofertados na merenda escolar. 
Exemplo dessa situação precária é a ausência de frutas, verduras e proteínas no cardápio da alimentação escolar disponibilizada na UC, sendo fornecidos apenas produtos industrializados $e$ processados, desrespeitando os hábitos culturais $e$ recomendações para uma alimentação saudável. Além disso, deixa de contribuir no incremento de renda dos comunitários e na valorização dos produtos regionais.

Diante disso, os produtores locais nunca tiveram acesso à comercialização de sua produção em mercados institucionais como o da alimentação escolar. Ou seja, a produção existente na RESEX nunca foi disponibilizada para consumo no ambiente das escolas locais.

\section{Objetivos}

O trabalho tem como objetivo geral fazer o levantamento dos dados de uma amostra da população de beneficiários da Reserva Extrativista Tapajós-Arapiuns sobre seu potencial de produção e disponibilidade comercial de gêneros alimentícios junto ao PNAE, para o fornecimento direto às escolas da rede pública inseridas na RESEX, visando desta forma promover a segurança alimentar nutricional e a geração de renda aos beneficiários da UC.

\section{Material e Métodos}

Trata-se da primeira Reserva Extrativista do estado do Pará, localizada nos municípios de Santarém (68,05\%) e Aveiro (31,95\%), com 74 comunidades, onde residem cerca 18.000 pessoas distribuídas em 3.500 famílias, população maior que a média de $33 \%$ dos municípios brasileiros. A RESEX apresenta o maior nível de escolaridade entre seus moradores, reflexo do quantitativo de 64 escolas de ensino fundamental em funcionamento (ICMBio, 2014).

$\mathrm{O}$ acesso à Reserva pode ser feito por via fluvial, a partir de Santarém pelos rios Tapajós e Arapiuns, navegando aproximadamente $2 \mathrm{~h}$ de lancha até a comunidade mais próxima (ICMBio, 2014).
Para o levantamento de dados neste trabalho, utilizou-se uma adaptação da abordagem metodológica participativa, através do Diagnóstico Rápido e Participativo de Agroecossistemas (DRPA) (Verdejo, 2006). A palavra "diagnóstico" nesse artigo é usada da mesma forma que um questionário ou formulário, entretanto sua aplicação é diferente dos métodos convencionais de pesquisas pois, busca diferentes fontes para assegurar uma coleta compreensível, como fotografias, observação direta em eventos, relatos e denúncias.

A forma de coleta de dados permite que os próprios comunitários pensem sistematicamente em seus problemas, nas possiveis soluções e que compartilhem com os mediadores do DRPA, para que compreendam as circunstâncias locais a as possíveis opções para enfrentá-las em conjunto.

As informações requeridas nos questionários foram baseadas nos dados do Edital da Semed, disponibilizado no site da Prefeitura Municipal de Santarém no dia 22 de fevereiro de 2019, com o título "Chamada Pública no 001/2019 - Semed" no portal da transparência.

Em campo, foram realizadas reuniões em 24 Escolas/Polo e respectivamente 24 comunidades, para a aplicação dos diagnósticos junto aos moradores (possíveis fornecedores de produtos alimentícios) e aos responsáveis pelas instituições de ensino (possíveis responsáveis pelo recebimento dos produtos), como professores, diretores ou conselheiros escolares. O número de representantes de cada escola variava, era necessário no mínimo um, para que as informações sobre as infraestruturas fossem precisas.

\section{Diagnóstico situacional da Escola Polo e da Comunidade Polo}

O estudo foi desenvolvido em 24 Escolas/ Polo do interior da Reserva Extrativista TapajósArapiuns, nos meses de novembro e dezembro de 2019 (Fig. 1). O conceito de Escola/Polo é pautado na concentração das atividades administrativas de uma escola em determinada comunidade da UC, esta escola pode ter unidades anexas que são subordinadas à Escola/Polo. 


\section{Localização das Escolas Polo e Anexas. \\ Reserva Extrativista Tapajós-Arapiuns}

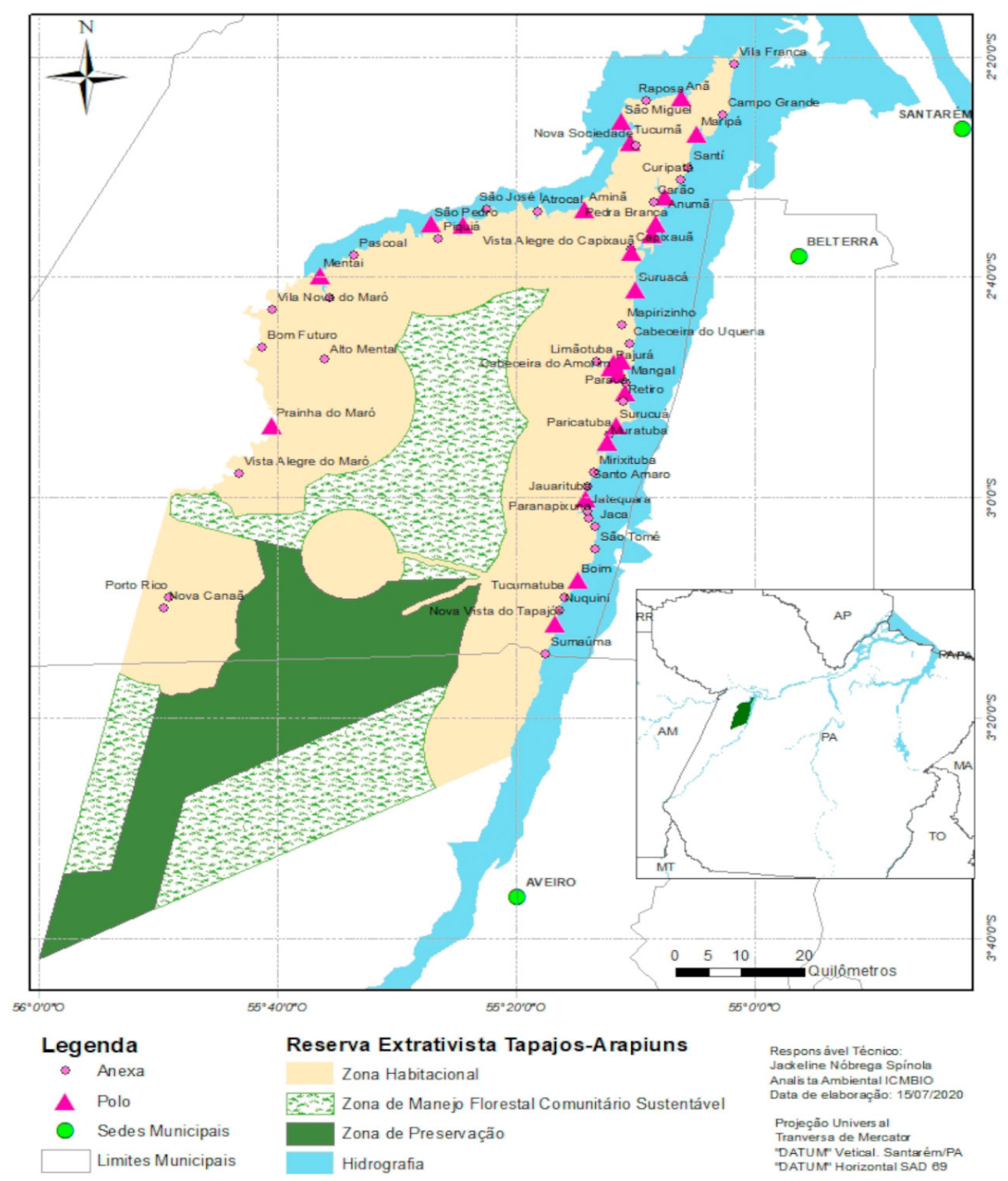

Figura 1 - Localização das Escolas/Polo que participaram do diagnóstico. Fonte: Spínola, 2020.

Nesta etapa, realizou-se um questionário semiestruturado com perguntas abertas objetivando identificar questões de acessibilidade e de infraestrutura para a recepção e abastecimento dos alimentos nas escolas abrangidas por este trabalho, bem como aspectos do envolvimento e organização comunitária na região de abrangência da escola (Tabela 1).
As perguntas dos questionários foram propostas pela equipe gestora do ICMBio $e$ buscaram trazer informações sobre o cenário atual da infraestrutura de logística de acesso, de armazenamento e de organização social da Comunidade Escolar, visando identificar gargalos e potencialidades para atendimento às especificações do edital da Semed. 
Tabela 1 - Questões sobre infraestrutura das Escolas/Polo.

\begin{tabular}{|l|l|}
\hline 1 & Nome da Comunidade / Sede: \\
\hline 2 & Nome da escola: \\
\hline 3 & Comunidades amparadas pela escola polo: \\
\hline 4 & Distância (em km) da escola-polo: \\
\hline 5 & $\begin{array}{l}\text { Principal meio de locomoção para acessar a escola- } \\
\text {-polo: }\end{array}$ \\
\hline 6 & Duração (em horas): \\
\hline 7 & Se a escola possui gerador: \\
\hline 8 & Se a comunidades possui associação legalizada: \\
\hline 9 & Se a escola possui conselho escolar: \\
\hline
\end{tabular}

Fonte: Autores, 2020.

\section{Diagnóstico do potencial produtivo por comunidade da Escola/Polo}

Foi aplicado o diagnóstico para identificação do potencial produtivo na área de abrangência das Escolas/Polo e a sazonalidade para distribuição do produto, tanto da produção agrícola quanto da criação de animais, utilizouse a ferramenta de Calendário Agrícola (Tabela 2).

Tabela 2 - Calendário agrícola por Escola/Polo.

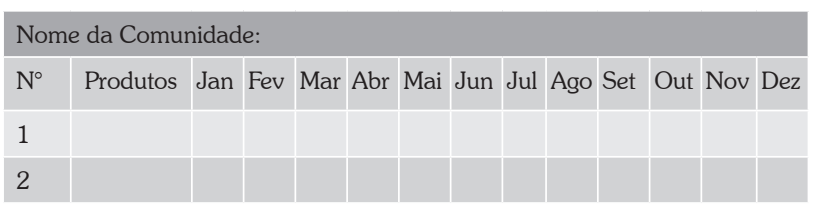

Fonte: Autores, 2020.

\section{Diagnóstico do potencial produtivo por unidade familiar}

Ao término do exercício coletivo de identificação do potencial produtivo da comunidade da Escola/Polo, os produtores foram convidados a realizar voluntariamente, o autopreenchimento do formulário intitulado "Diagnóstico do potencial produtivo por produtor", de acordo com seu interesse em comercializar sua produção diretamente na escola, via Semed.

Para essa etapa, foi estipulado um prazo de 30 dias para que o produtor pudesse fazer uma reflexão e discussão no contexto familiar sobre o assunto, com posterior envio do formulário preenchido ao ICMBio.

Diferentemente dos diagnósticos anteriores, que possuíam uma dinâmica coletiva, este foi executado no núcleo familiar do produtor, sendo possível analisar, posteriormente, o total da produção anual por família, bem como se teriam condições de atender à demanda do edital de Semed/2019 e, por fim, identificar quais produtores necessitariam da Declaração de Aptidão ao Programa Nacional de Fortalecimento da Agricultura Familiar, pré-requisito para participação no edital.

Tabela 3 - Formulário com informações pessoais do produtor bem como seu potencial de produção a longo do ano.

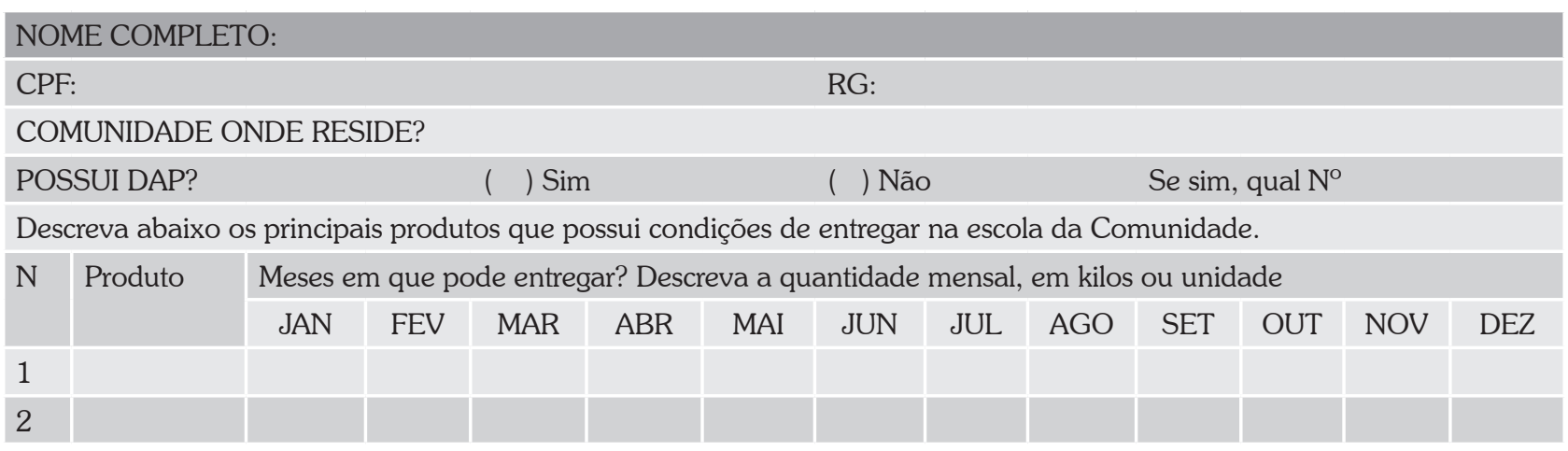

Fonte: Autores, 2020.

\section{Resultados e discussão}

\section{Diagnóstico situacional da Escola/Polo e da Comunidade Polo}

Um dos principais desafios da distribuição e entrega da alimentação escolar na região da RESEX é a logística de acesso até as comunidades, que é predominantemente fluvial, bem como a inexistência de infraestrutura para manutenção refrigerada dos produtos, pois as comunidades da UC não estão interligadas à rede de distribuição de energia elétrica. 
Nas reuniões realizadas, 24 Escolas/Polos responderam o formulário sobre infraestruturas e $100 \%$ destas afirmaram possuir gerador de energia e manifestaram-se positivamente quanto ao uso dos mesmos para manutenção ou processamento de alimentos.

No entanto, na distribuição pela Semed, os barcos não possuem os equipamentos necessários, por exemplo as câmaras frigoríficas, para que os alimentos cheguem em condições adequadas, pois em certas localidades são praticamente 24 horas de deslocamento. Em Ramos et al. (2017) é demonstrado que a entrega pode ser realizada em ação conjunta da associação e da prefeitura; nesse sentido, é interessante analisar a possibilidade da terceirização do transporte além da busca $e$ organização das associações com outras cooperativas e empresas.

Em relação à distância das escolasanexas, que são amparadas ou atendidas pela Escola/Polo, o principal meio de locomoção são as bajaras (pequenas embarcações movidas a motor de popa), por via fluvial, levando cerca de 1 ou até 4 horas até a polo mais próxima, na região dos rios Arapiuns e Maró. As comunidades na margem do rio Tapajós possuem maior facilidade em locomoção dentro da área em virtude dos ramais de acesso que interligam as comunidades, tendo como principal meio de locomoção, motos que levam em média 30 minutos.

Todas as Escolas/Polo avaliadas declararam possuir o Conselho de Alimentação Escolar (CAE), um dos principais mecanismos de controle social e que avalia a qualidade do produto ofertado na merenda escolar. No Caderno de Práticas Premiadas de Controle Social do PNAE, é apresentado o êxito do Conselho de Alimentação Escolar de Barcarena/ PA junto de várias parcerias governamentais $e$ não governamentais, incentivando e apoiando mutualmente, através de reuniões e formações para mais conselheiros. Além da divulgação para toda a sociedade, explanando formas de contribuir para o programa, dessa forma, a organização do CAE é um dos principais mecanismos para a gestão e organização do programa nas escolas da RESEX, pois é a partir deles que é possível mudar a gestão das refeições.
Em apenas uma Escola/Polo, a comunidade local declarou não possuir associação legalizada, fator que é relevante e se apresenta como pré-requisitoparaparticipaçãodaorganizaçãosocial na Chamada Pública. No estudo de Turpin (2009), são analisados os melhores mecanismos para o PNAE; $e$ foi usada como base de dados a $3^{\mathrm{a}}$ edição do Prêmio Gestor Eficiente da Merenda Escolar. Cerca de 610 prefeituras de todo o país responderam questões sobre o programa e, entre as vencedoras, é demonstrado que a principal forma de apoio ao agricultor familiar foi através da compra por cooperativa/associação.

No trabalho de Belik \& Chaim (2009) também é usada a mesma base de dados que em Turpin (2009) e é apresentado que esse modo de organização impulsiona o desenvolvimento local, porque engloba outras instituições que prestam apoio aos agricultores, por exemplo, por meio da criação de leis municipais. Dessa forma, é importante salientar que, além dos agricultores participarem, outros órgãos também devem colaborar para a melhoria do programa.

A partir dos nomes das instituições repassados pelos responsáveis das escolas, foi feito o comparativo no site oficial do PNAE, no Censo escolar, na qual é possível fazer o levantamento do número de alunos e quais modalidades a escola atende, para assim ser estipulado a quantidade dos produtos. Entretanto, os dados não estão de acordo quanto aos nomes repassados, pois a maioria dos registros não é encontrada no site oficial, ou há duplicação dos nomes, haja vista vários deles estarem repetidos.

\section{Diagnóstico do potencial produtivo por região da Escola/Polo}

Das 24 comunidades que participaram da elaboração do diagnóstico, foi possível identificar um total de 64 produtos potenciais para oferta dentro do cardápio da merenda escolar (Tabela 4). Dessa ampla gama de produtos, destacam-se pelo menos 10 que estão presentes em pelo menos 20 comunidades $(91 \%)$. 
Tabela 4 - Principais produtos disponíveis em mais de $90 \%$ das comunidades amostradas.

\begin{tabular}{|l|l|c|}
\hline$N^{\circ}$ & Produtos & $\begin{array}{l}\text { No de comunidades que } \\
\text { produzem }\end{array}$ \\
\hline 1 & Farinha de mandioca & 22 \\
\hline 2 & Galinha caipira & 22 \\
\hline 3 & Muruci & 22 \\
\hline 4 & Macaxeira & 22 \\
\hline 5 & Cupuaçu & 21 \\
\hline 6 & Farinha de tapioca & 21 \\
\hline 7 & Ovo & 21 \\
\hline 8 & Cará & 20 \\
\hline 9 & Banana & 20 \\
\hline 10 & Bacaba & 20 \\
\hline
\end{tabular}

Fonte: Autores, 2020.

Destaca-se que as principais fontes de proteína animal (galinha e ovo) com potencial de fornecimento na alimentação escolar estão presentes em pelo menos $91 \%$ das comunidades. No entanto, esses mesmos alimentos não são abrangidos pelo edital.

Em comparação, Gabriel et al. (2012) verificaram que os cardápios das escolas em Florianópolis possuem diversidades entre as mesmas, mas, em Belém, os cardápios são padronizados e a baixa oferta de frutas e hortaliças também está presente, fator evidenciado na RESEX por conta do transporte. Apesar de o edital ser considerado adaptado, não são todas as cidades que apresentam a mesma diversidade e estrutura exigida.

\section{Diagnóstico do potencial produtivo por produtor}

Somente os representantes de 16 localidades participaram desta etapa. O formulário sobre o potencial produtivo e de entrega dos alimentos escolares da unidade familiar foi preenchido por 123 famílias, destas apenas 6 possuem a DAP, documento necessário para habilitar-se a comercialização junto a mercados institucionais e que identifica o produtor rural como beneficiário e é um dos critérios, para o acesso a política pública nacional do PNAE.

Dessa forma, os 117 produtores que não possuem a DAP foram convidados a ir a sede do ICMBio em Santarém, fazer o cadastro no caso desejassem. As comunidades de Surucuá e Prainha do Maró foram as que apresentaram maior interesse e preencheram uma maior quantidade de formulários (Tabela 5). Observou-se que apenas $12 \%$ do total das famílias residentes nessas comunidades tiverem interesse em participar do diagnóstico e candidatar-se à comercialização de sua produção.

Tabela 5 - Total de famílias por comunidades e número de questionários respondidos.

\begin{tabular}{|c|c|c|c|c|}
\hline \multirow[t]{2}{*}{$\mathrm{N}^{\circ}$} & \multirow[t]{2}{*}{ Comunidades } & \multirow{2}{*}{$\begin{array}{l}\mathrm{N}^{\circ} \text { famílias } \\
\text { residentes }\end{array}$} & \multicolumn{2}{|c|}{$\begin{array}{l}\mathrm{N}^{\circ} \text { famílias que } \\
\text { responderam }\end{array}$} \\
\hline & & & Unidades & $(\%)$ \\
\hline 1 & $\begin{array}{l}\text { Prainha do } \\
\text { Maró }\end{array}$ & 56 & 35 & 62,50 \\
\hline 2 & Suruacá & 129 & 25 & 19,38 \\
\hline 3 & Anã & 87 & 8 & 9,20 \\
\hline 4 & Parauá & 151 & 9 & 5,96 \\
\hline 5 & $\begin{array}{l}\text { Cabeceira do } \\
\text { Amorim }\end{array}$ & 69 & 9 & 13,04 \\
\hline 6 & $\begin{array}{l}\text { Nova } \\
\text { sociedade }\end{array}$ & 38 & 6 & 15,79 \\
\hline 7 & Solimões & 44 & 5 & 11,36 \\
\hline 8 & Maripá & 72 & 4 & 5,56 \\
\hline 9 & Muratuba & 80 & 4 & 5,00 \\
\hline 10 & Aldeia Pajurá & 22 & 4 & 18,2 \\
\hline 11 & Tucumatuba & 75 & 3 & 4,00 \\
\hline 12 & $\begin{array}{l}\text { Vista Alegre } \\
\text { do Maró }\end{array}$ & 24 & 6 & 25,00 \\
\hline 13 & Retiro & 31 & 2 & 6,45 \\
\hline 14 & Capixauã & 43 & 1 & 2,08 \\
\hline 15 & $\begin{array}{l}\text { Vila Nova do } \\
\text { Maró }\end{array}$ & 19 & 1 & 12,45 \\
\hline \multirow[t]{2}{*}{16} & Aminã & 48 & 1 & 2,10 \\
\hline & Total & 988 & 123 & 12,24 \\
\hline
\end{tabular}

Fonte: Autores, 2020.

Importante frisar que este quantitativo se refere à intencionalidade dos produtores em entregar determinado produto nas escolas de suas comunidades, não refletindo diretamente a capacidade de produção que em alguns casos pode estar sub ou superestimada.

Entre os 10 produtos com maior potencial produtivo na RESEX, destaca-se a farinha, que é a base da alimentação dos moradores da região e também a principal fonte de renda, pois é o principal produto comercializado pelos mesmos, totalizando cerca de 43 mil quilos por ano, o que equivale a uma renda aproximada de 200 mil reais/ano para um total de 123 famílias, levando em consideração o valor da farinha no edital da Semed, no valor de $\mathrm{R} \$ 4,83$ por quilo. 
Os derivados desse cultivo também possuem relevância, pois se configuram em $2^{\circ}, 4^{\circ}$ e $7^{\circ}$ lugar (macaxeira, goma de tapioca e farinha), totalizando cerca 26,5 toneladas. Entre as frutas, destacam-se a banana, com cerca de 7 mil quilos, e o abacaxi com cerca de 2,3 mil quilos.
Entretanto, esse quantitativo não é o suficiente para atender o município de Santarém. Importante salientar que o edital proposto atende todas as escolas do município.

Observa-se a ausência ou baixa quantidade disponível para os alimentos de origem animal (galinha e ovos) e hortaliças (Fig. 2).

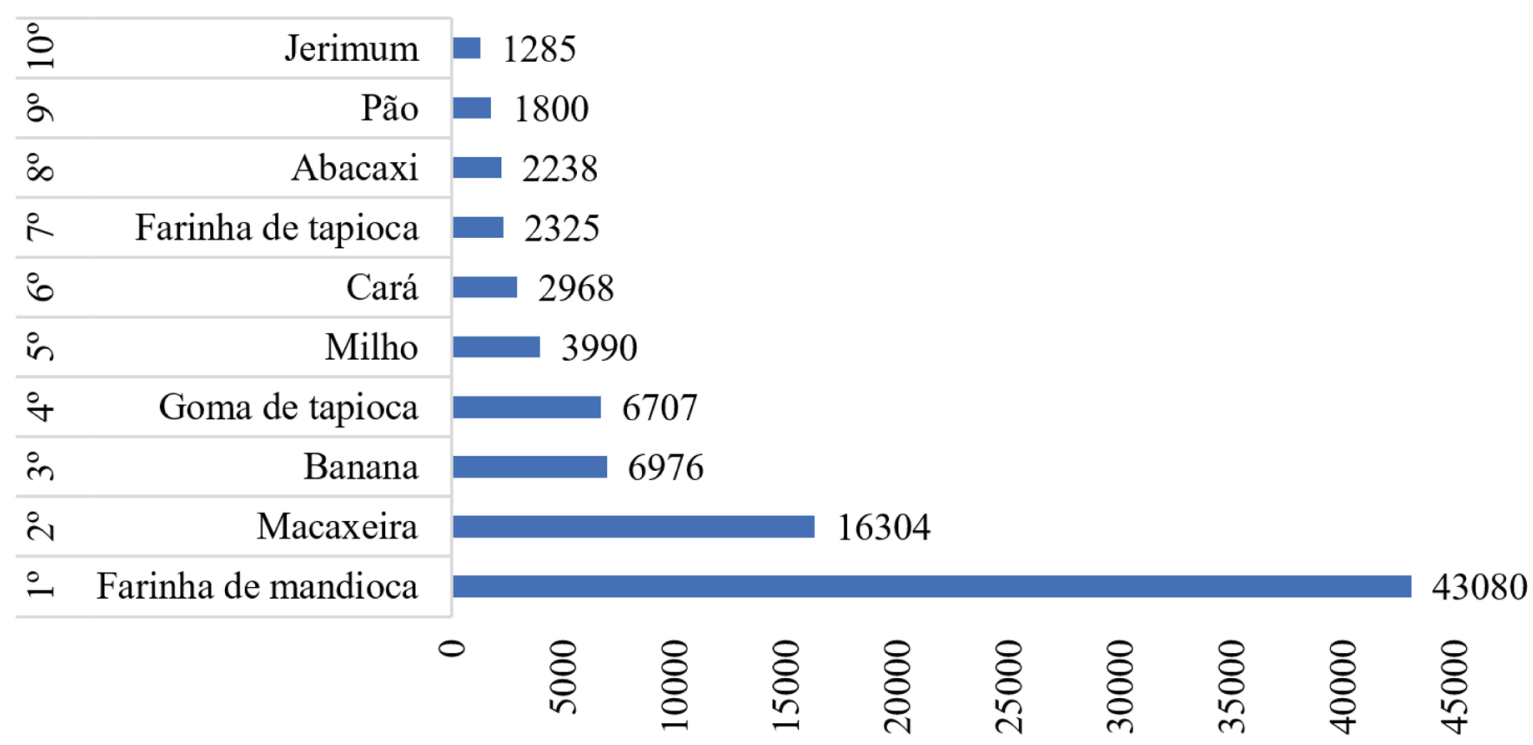

Figura 2 - Estimativa da capacidade de produção e entrega nas escolas da RESEX pelos entrevistados. Fonte: Autores, 2020.

Como poucas famílias responderam o questionário, é possível que, com a continuação da aplicação dos diagnósticos, a produção da UC possa atender ao exigido da Chamada Pública.

A importância da valorização da agricultura familiar através da inclusão dos seus produtos nas escolas, é de grande relevância como afirma Abramovay (1999) "as políticas voltadas para o fortalecimento e para a criação de novas unidades familiares no meio rural terão tanto mais sucessos quanto mais importantes forem as oportunidades de intensificação de suas ligações dinâmicas e diversificadas com as cidades".

\section{Aspectos estruturantes da distribuição da Merenda Escolar na Resex}

De acordo com a Resolução n ${ }^{\circ} 26$ do Fundo Nacional de Desenvolvimento da Educação, o programa possui algumas restrições:

É vedada a aquisição de bebidas com baixo valor nutricional tais como refrigerantes e refrescos artificiais, bebidas ou concentrados à base de xarope de guaraná ou groselha, chás prontos para consumo e outras bebidas similares.

É restrita a aquisição de alimentos enlatados, embutidos, doces, alimentos compostos (dois ou mais alimentos embalados separadamente para consumo conjunto), preparações semiprontas ou prontas para o consumo, ou alimentos concentrados (em pó ou desidratados para reconstituição). (BRASIL, 2013 - arts. 22 e 23).

Entretanto, alimentos como achocolatados, sardinha, refrigerantes e bebidas em pó (Fig. 3B e 3C) fazem parte da alimentação dos alunos. Houve aumento de até $400 \%$ no consumo de produtos industrializados, como biscoitos e refrigerantes, persistência do consumo excessivo do açúcar $e$ insuficiência de frutas e hortaliças, e aumento sistemático no teor da dieta em gorduras em geral e em gorduras saturadas (Triches, 2009). Dessa maneira, reforça a importância das políticas públicas voltadas para a reversão do atual quadro onde cada vez mais alimentos industrializados são consumidos em detrimento dos "in natura" Silva et al. (2015). 
Importante salientar o déficit de produtos comprados para a alimentação, principalmente a proteína animal, demonstrado no cardápio das escolas na RESEX, fornecido pela Secretaria Municipal de Educação, Divisão de Atendimento ao Educando, em que as escolas da região do Arapiuns não recebem nenhum tipo de proteína animal, a não ser industrializadas como sardinhas em conversa, almôndega bovina ao molho e salsicha ao molho de tomate. As escolas da região do Tapajós recebem esses mesmos produtos, mas com o adicional de carne moída, isca de paleta e coxa e sobrecoxa de frango.

O cardápio das escolas não está adequado à oferta de alimentos das comunidades, apesar de ser condizente com gêneros alimentícios da região Norte, o que foi evidenciado é o uso de enlatados como solução dos problemas justapostos à infraestrutura e distância. Nenhuma das comunidades apresenta a rede elétrica, fator que dificulta a preservação dos alimentos e em algumas a estrutura das escolas ainda é extremamente simples, como na comunidade Prainha do Maró, (Fig. 3A, $3 \mathrm{D}$ e $3 \mathrm{E})$. Além dos barcos não possuírem as câmaras frias, todos os produtos são mantidos em temperatura ambiente nas comunidades, ou seja, é extremamente difícil a preservação levando em conta o clima da região Norte que acelera a decomposição, como afirma Silva et al. (2018), o clima é predominante tropical úmido, oscila estre estações chuvosas e secas.

Por meio das visitas nas escolas, foi possível observar que, apesar das leis para o fornecimento e criação de cardápios, a realidade é bem diferente. Isso demonstra que é importante que outros trabalhos avaliem a efetividade do programa na região Norte do Brasil e através de parcerias com as universidades federais do Estado com agricultores e cooperativas seja possível a construção de diferentes parâmetros.

A adequação dos produtos para o clima da região poderia ser feita com a substituição das polpas de frutas por frutas in natura, por exemplo. Todas as comunidades demonstraram no diagnóstico, que possuem produtos para ofertar, entretanto o edital da Semed não é contemplado esses produtos.
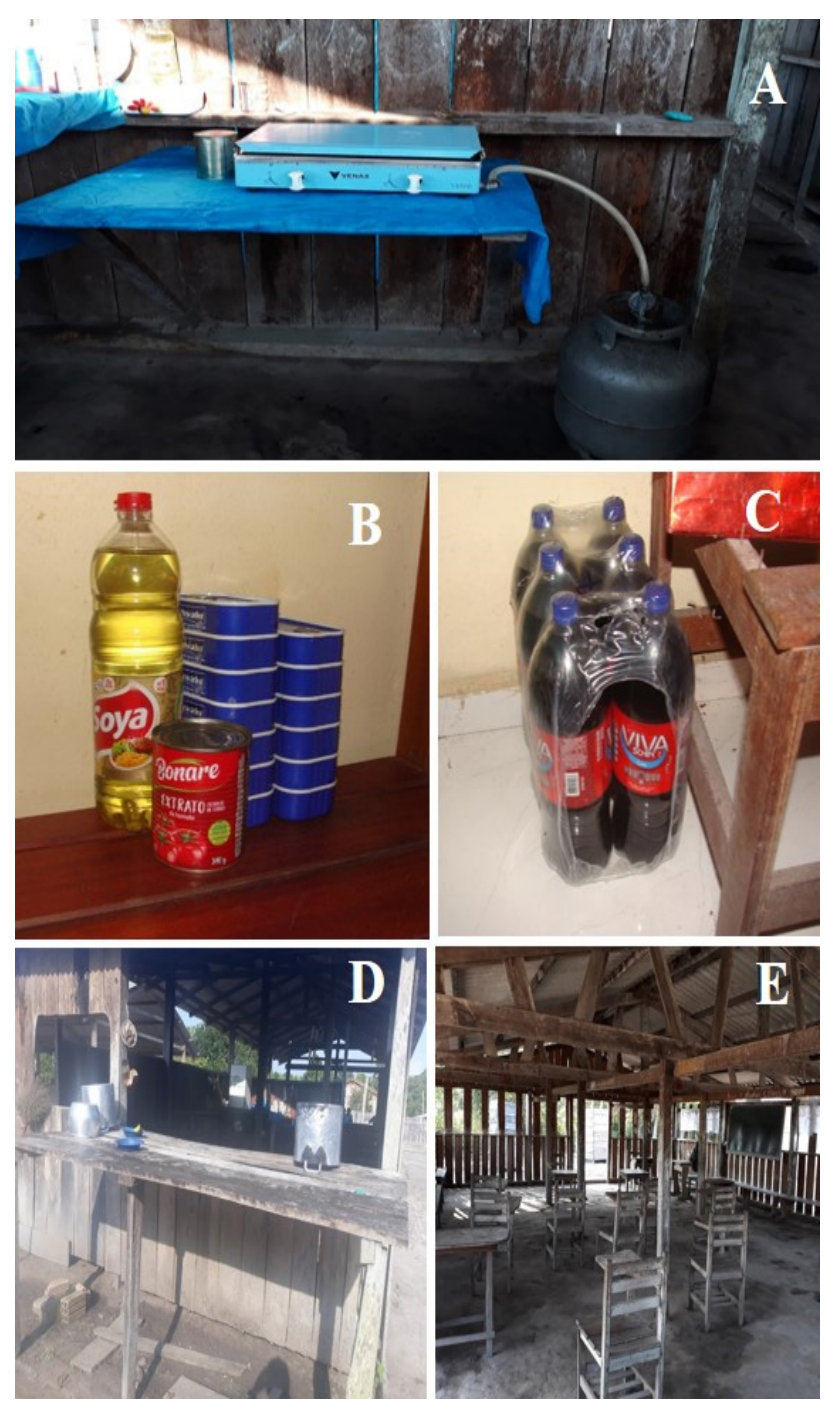

Figura 3 - Estrutura e alimentos das instituições: A) fogão da escola Prainha do Maró; B) alimentos ultra processados na dispensa; C) refrigerante de cola; D) jirau de madeira; e E) sala de aula. Fontes: Autores, 2020.

A falta de estrutura é um dos maiores entraves em algumas comunidades. São necessárias parcerias das cooperativas como, por exemplo, com a Empresa de Assistência Técnica e Extensão Rural (EMATER), que, na tese de Silva (2015), mostra o processo da Associação dos Produtores Rurais e Urbanos Carlos Pena Filho (APRUCAPEFI) da cidade de Altamira, Pará, quanto à colaboração dos técnicos na elaboração de alternativas e regulamentação de documentos para os agricultores acessarem a política pública. 
De acordo com Wagner (2015), é importante haver comunicação entre os atores envolvidos (agricultores familiares, gestores públicos, organizações, dentre outros) para que seja discutido em conjuntos as dificuldades $e$ parcerias necessárias para alcançar a melhoria nas refeições e estruturas.

Apesar da importância do presente trabalho, é visto pouca colaboração das entidades responsáveis pela alimentação escolar em disponibilizar os dados oficiais. Dessa forma, a pesquisa requer mais tempo para a elaboração $e$ discussão de estratégias. Assim como na RESEX, em Gabriel et al. (2012), é feita comparação do programa em duas capitais, Florianópolis e Belém. Ambas apresentaram que, apesar do PNAE incentivar a aquisição pelos agricultores familiares, não dispõem de mecanismos suficientes para a inclusão dos insumos no edital de licitação, fato que acarreta uma competição com produtores de outros estados, já que os produtores da região não conseguem produzir o suficiente, ter a estrutura necessária e entender os processos burocráticos.

De acordo com Sonnino (2007), no Reino Unido e Itália, quando os diretores das escolas começaram a fazer a gestão da alimentação escolar, a compra passou a ser diretamente dos agricultores da região, sem intermediários no processo. Além de incentivar a produção local, os custos com alimentação foram reduzidos e os produtos possuíam melhor qualidade.

Essa seria uma boa alternativa para os comunitários da RESEX; pois entregariam sua produção diretamente nas escolas, sendo necessário apenas pequenas alterações na frequência das entregas e dispensando a necessidade da refrigeração dos produtos.

A criação de um edital exclusivo para a região também poderia beneficiar os comunitários e alunos, pois, em vez de o alimento ser entregue em Santarém, seria feita a entrega diretamente nas Escolas/Polo.

\section{Conclusões}

Com base nos resultados obtidos, é possível concluir que os comunitários apresentaram disponibilidade para a comercialização dos gêneros junto ao PNAE para as escolas na RESEX, porém é necessário buscar articulação com as entidades responsáveis pela merenda escolar em Santarém, bem como recursos para melhorar a infraestrutura de armazenamento e beneficiamento de alimentos nas escolas.

Alimentos como a galinha caipira e o ovo apresentaram boa distribuição regional, mas necessitam de fomento à produção e capacitação aos produtores para melhoria das práticas de cultivo e abate para atendimento às exigências sanitárias dos editais de aquisição de alimentos para merenda escolar pela Semed.

É necessário investir na variabilidade de produção na RESEX. Observou-se que o enfoque produtivo é apenas a produção de farinha. Através da realização de oficinas e projetos, outras atividades produtivas devem ser apresentadas com vistas a diversificar a produção.

Devem-se buscar formas de fortalecer $e$ organizar as associações e conselhos escolares, com vista a viabilizar a participação em editais de mercados institucionais da região para $\mathrm{o}$ fornecimento direto.

\section{Recomendações para a gestão}

O levantamento de dados deve ter continuidade nas outras comunidades em que os diagnósticos não foram aplicados, para que mais dados sejam coletados e tragam informações mais precisas sobre a quantidade de produtos disponíveis por produtor, com conclusões mais seguras sobre o potencial produtivo e possibilitando talvez o fornecimento direto na RESEX.

Outra recomendação importante é a articulação entre os órgãos responsáveis pela alimentação escolar na região de Santarém, para elaborar estratégias e projetos a partir dos resultados obtidos da presente pesquisa. 


\section{Referências}

Abramovay, R. Agricultura familiar e desenvolvimento territorial. Revista da Associação Brasileira de Reforma Agrária - vols. 28 nos 1,2 3 e 29, no1 - Jan/dez, 1999. <http://www.ifibe.edu.br/ arq/201508131525281087273037.pdf > . Acesso em: 30/10/2020.

Brasil. 2009. Lei $\mathrm{n}^{\circ} 11.947$, de 16 de junho de 2009. Diário Oficial da União. <http://www.planalto.gov.br/ ccivil_03/_Ato2007-2010/2009/Lei/L11947.htm > . Acesso em: 01/02/2020.

Brasil. Ministério da Educação. Fundo Nacional de Desenvolvimento da Educação. Cadernos de Práticas Premiadas de Controle Social do PNAE - Relatos Premiados no Prémio CAE de Participação Social Brasília: MEC, 2019.

Brasil. Ministério da Educação. Fundo Nacional de Desenvolvimento da Educação. Resolução n ${ }^{\circ}$ 26, de 17 de junho de 2013. Brasília: MEC, 2013. <https:/www. in.gov.br/materia//asset_publisher/Kujrw0TZC2Mb/ content/id/30683767/do1-2013-06-18-resolucao-n26-de-17-de-junho-de-2013-30683763>. Acesso em: 13/08/2020.

Belik W \& Chaim NA. O programa nacional de alimentação escolar e a gestão municipal: eficiência administrativa, controle social e desenvolvimento local. Revista Nutricional Campinas. 22(5): 595-607, 2009.

Gabriel CG, Costa LC, Calvo MCM, Vasconcelos FAG. Planejamento de cardápios para escolas públicas municipais: reflexão e ilustração desse processo em duas capitais brasileiras. Revista de Nutrição, 25(3): 363-372, 2012.

ICMBio/MMA. Plano de Manejo Reserva Extrativista Tapajós-Arapiuns. Volume 1. Brasília/DF: ICMBio, 2014. 56p.

Ramos MS, Maneschy RQ, Queiroz JF, Marques MNC \& Chaves THM. Produtos da Agricultura Familiar na alimentação escolar do Município de Curuça-PA: Desafios e Perspectivas. Revista Agroecossistemas, 9(1): 131-146, 2017.
Prefeitura Municipal de Santarém, Portal da Transparência. Disponível em: <https://transparencia.santarem.pa.gov.br/ storage/anexos/licitacoes/20171104/2019/04/29/editalda-licitacao-no-0012019e61df111-ec81-4eb8-b8e1bf65ad19130e.pdf>. Acesso em: 28/10/2020.

Silva, DW. Produzindo prerrogativas de cidadania: o acesso da agricultura familiar à política de fornecimento de produtos para a alimentação escolar. Tese (Doutorado em Desenvolvimento Rural) - Universidade Federal do Rio Grande do Sul, Porto Alegre, 2015. < https://www. lume.ufrgs.br/handle/10183/147454>. Acesso em: 28/10/2020.

Sonnino R. The power of place: embeddedness and local food systems in Italy and the UK. Anthropology of food, S2, 2007. < https://journals.openedition.org/ aof/454>. Acesso em: 06/08/2020.

Silva EC, Silva TR, Ló JS, Lima AKA \& Oliveira JJMB. Diversidade de Odonata (Insecta) em igarapés na Reserva Extrativista Tapajós-Arapiuns (PA). Revista Ibero Americana de Ciências Ambientais, 9(6): 109 119, 2018.

Silva CVA, Paulino GS \& Souza AL. Agricultura Familiar e Mercado Institucional de Alimentos: ensaio crítico a partir de um projeto de extensão. VII Jornada Internacional Políticas Públicas, 2015. <http://www. joinpp.ufma.br/jornadas/joinpp2015/pdfs/eixo10/ agricultura-familiar-e mercado-institucional-dealimentos-ensaio-critico-a-partir-de-um-projeto-depesquisa e extensao.pdf $>$. Acesso em: 25/10/2020.

Turpin ME. A Alimentação Escolar como Fator de Desenvolvimento Local por meio do Apoio aos Agricultores Familiares. Revista Segurança Alimentar e Nutricional, 16(2): 31-42, 2009.

Triches RM, Froehlich E \& Schneider S. Relações de produção e consumo: a aquisição de produtos da agricultura familiar para o Programa de Alimentação Escolar. Anal do congresso espanõl de Sociología de la alimentação de Agroecologia Gijón. 2009.

Verdejo ME. Diagnóstico rural participativo: guia prático DRP - Brasília: MDA/Secretaria da Agricultura Familiar, 2006, 62p.

Biodiversidade Brasileira - BioBrasil.

Edição Temática: PIBIC

n. 1,2022

http://www.icmbio.gov.br/revistaeletronica/index.php/BioBR

Biodiversidade Brasileira é uma publicação eletrônica científica do Instituto Chico Mendes de

Conservação da Biodiversidade (ICMBio) que tem como objetivo fomentar a discussão $e$ a disseminação de experiências em conservação e manejo, com foco em unidades de conservação $e$ espécies ameaçadas.

ISSN: 2236-2886 